Int. J. Electrochem. Sci., 11 (2016) 3803 - 3814

International Journal of

ELECTROCHEMICAL

SCIENCE

www.electrochemsci.org

\title{
Electrodeposited Nanoporous PtY Alloy Electrodes with Enhanced Oxygen Reduction Reaction
}

Sang-Beom Han, Da-Hee Kwak, Young-Woo Lee, Si-Jin Kim, Jin-Yeon Lee, Seul Lee, Hye-Jin Kwon, and Kyung-Won Park*

Department of Chemical Engineering, Soongsil University, Seoul 156-743, Korea

*E-mail: kwpark@ssu.ac.kr

doi: $10.20964 / 110380$

Received: 18 January 2016 / Accepted: 11 March 2016 / Published: 1 April 2016

Pt-based alloy nanostructures are known to exhibit improved electrocatalytic properties due to their particularly modulated surface and electronic structures favourable for oxygen reduction reactions. Here, we report nanoporous PtY alloy electrodes fabricated using electrodeposition method at a high reduction potential in anhydrous metal salt solutions. The as-deposited PtY electrodes show a nanoporous well-defined alloy nanostructure via transmission electron microscopy and X-ray diffraction methods. The PtY alloy electrodes exhibit enhanced electrochemical activity for ORR, i.e. higher specific current and half-wave potential in ORR compared with a conventional Pt electrocatalyst. The improved electrochemical activity of the electrodeposited PtY electrodes in ORR is ascribed to the nanoporous structure and alloy surface due to the $\mathrm{Y}$ atoms in the alloy phase.

Keywords: Nanoporous, Platinum, Yttrium, Alloy, Electrodeposition, Oxygen reduction reaction

\section{FULL TEXT}

(C) 2016 The Authors. Published by ESG (www.electrochemsci.org). This article is an open access article distributed under the terms and conditions of the Creative Commons Attribution license (http://creativecommons.org/licenses/by/4.0/). 